\title{
A local ionospheric model for forecasting the critical frequency of the F2 layer during disturbed geomagnetic and ionospheric conditions
}

\author{
M. Pietrella and L. Perrone \\ Istituto Nazionale di Geofisica e Vulcanologia, via di Vigna Murata 605, 00143 Rome, Italy \\ Received: 10 January 2007 - Revised: 22 March 2007 - Accepted: 9 July 2007 - Published: 26 February 2008
}

\begin{abstract}
An ionospheric forecasting empirical local model over Rome (IFELMOR) has been developed to predict the state of the critical frequency of the F2 layer $(f o \mathrm{~F} 2)$ during geomagnetic storms and disturbed ionospheric conditions. Hourly measurements of $f o \mathrm{~F} 2$ obtained at the Rome observatory, hourly quiet-time values of $f o \mathrm{~F} 2(f \circ \mathrm{F} 2 Q T)$, and the hourly time-weighted accumulation series derived from the geomagnetic planetary index $a_{p}\left(a_{p}(\tau)\right)$, were considered during the period January 1976-December 2003. Under the assumption that the ionospheric disturbance index $\log \left(f o \mathrm{~F} 2 / f o \mathrm{~F} 2{ }_{Q T}\right)$ is correlated to the integrated geomagnetic index $a_{p}(\tau)$, statistically significant regression coefficients are obtained for different months and for different ranges of $a_{p}(\tau)$ and used as input to calculate the short-term ionospheric forecasting of $f o \mathrm{~F} 2$. The empirical storm-time ionospheric correction model (STORM) was used to make comparisons with the IFELMOR model. A few comparisons between STORM's performance, IFELMOR's performance, the median measurements and the $f_{O} \mathrm{~F} 2 Q T$ values, were made for significant geomagnetic storm events $\left(a_{p}>150\right)$ occurring from 2000 to 2003 . The results provided by IFELMOR are satisfactory, in particular, for periods characterized by high geomagnetic activity and very disturbed ionospheric conditions.
\end{abstract}

Keywords. Ionosphere (Ionosphere-magnetosphere interactions; Ionospheric disturbances; Modeling and forecasting)

\section{Introduction}

A large number of global (Jones and Gallet, 1962; Comite Consultatif International des Radio Communications (CCIR), 1991; International Telecommunication Union (ITU), 1997) and regional models (Bradley, 1999; Hanbaba,

Correspondence to: M. Pietrella

(pietrella@ingv.it)
1999) have been developed over the years in order to predict the monthly medians of the key ionospheric characteristic of the F2 layer, such as its critical frequency, $f o \mathrm{~F} 2$, and the obliquity factor for a distance of $3000 \mathrm{~km}, \mathrm{M}(3000) \mathrm{F} 2$. Other long term prediction models such as IPS-ASAPS and ICEPAC are also able to predict the sky wave communication conditions in the HF radio spectrum: IPS-ASAPS (Advanced Stand Alone Prediction System) is based on ITU-R/CCIR models (Rec. ITU-R P.533-8, Rec. ITU-R P.372-8 and CCIR Reports 322), and on an ionospheric model developed by the IPS Radio and Space Services of the Australian Department of Industry, Tourism and Resources (IPS-Radio and Space Services, undated); ICEPAC ((Ionospheric Communications Enhanced Profile Analysis and Circuit) is a full system performance model for HF radio communication circuits (Stewart F.G, undated).

As recent studies have shown, ASAPS and ICEPAC provide good guidelines for the choice of the maximum usable frequencies (MUF) that need to be used in radio communications under "quiet" ionospheric conditions (Zolesi et al., 2007).

The situation is completely different under "disturbed" ionospheric conditions related to geomagnetic storm events.

A large number of studies concerning ionospheric storms have been carried out in the past. From several experimental and theoretical studies a phenomenological scenario of the ionospheric response to geomagnetic storms has emerged (see reviews by: Prölss, 1995, 1997; Fuller-Rowell et al., 1997; Buonsanto, 1999). Therefore it is well known that solar wind particles of increased speed and/or density, caused by solar disturbances such as coronal mass ejection, captured by the Earth's magnetosphere, cause changes in the Earth's magnetic field giving raise to the so called geomagnetic storms.

During such events large energy inputs, taking the form of enhanced electric fields, currents, and energetic particle precipitation, cause a noticeable joule heating of the

Published by Copernicus Publications on behalf of the European Geosciences Union. 
atmospheric gases. The resulting expansion of the thermosphere at high latitudes alters the composition of the neutral air, especially the atomic oxygen $[\mathrm{O}]$, the molecular nitrogen $\left[\mathrm{N}_{2}\right]$ and the molecular oxygen $\left[\mathrm{O}_{2}\right]$. The vertical motion of these species can result in a decrease in the $[\mathrm{O}] /\left[\mathrm{N}_{2}\right]$ and $[\mathrm{O}] /\left[\mathrm{O}_{2}\right]$ ratios (Rishbeth et al., 1987) which strongly affect the electron density of the $\mathrm{F} 2$ region.

When the heating events are impulsive, the expansion of the atmosphere also produces winds that transport the composition changes from higher to lower latitudes manifesting themselves as motions of the neutral atmosphere on a large scale (Richmond and Matsushita, 1975; Roble et al., 1978: Burns and Killen, 1992; Hocke and Schlegel, 1996). These motions, more properly called gravity waves $(\mathrm{GW})$, have their origin in the auroral zones. Testud (1970) and Titheridge (1971) have shown that GW are observed much more frequently when geomagnetic activity is particularly marked i.e. in the course of geomagnetic storm events. Observations concerning the oscillations of electron density suggest the GW activity in the $F$ region of the ionosphere (Pietrella et al., 1997). The GW activity generates wavelike motions called travelling ionospheric disturbances (TIDs) that can play an important role in changing ionization, making HF communications difficult.

Therefore, during geomagnetic storm events important changes in the content of electron density can alter the dayto-day F region ionospheric variability. The ionization density can either increase or decrease during disturbed conditions. These changes are denoted as negative or positive ionospheric storms, according to whether $f o \mathrm{~F} 2$ is below or above its "quiet value", respectively.

The long term prediction models for $f o \mathrm{~F} 2$ are not able to provide good forecasts in the course of ionospheric storms when considerable reductions of $f o \mathrm{~F} 2$ can occur. During such events, the monthly median models, like ASAPS and ICEPAC, are not appropriate for forecasting the depletion of MUF that represents a serious drawback in maintaining efficient management of HF radio communications. As a result, there is a need to develop now-casting models (AraujoPradere et al., 2002; Zolesi et al., 2004; Pietrella and Perrone, 2005) and short-term forecasting models (Cander et al., 1998; Muhtarov and Kutiev, 1999; Oyeyemi et al., 2005) for the prediction of $f o \mathrm{~F} 2$ for a few hours ahead. This would provide HF operators with real-time or quasi-real-time assistance in choosing the optimal frequencies for radio links, even in the case of a strongly disturbed ionosphere.

The problem of forecasting the ionospheric disturbances associated with geomagnetic storms has already been examined in the past. Many geomagnetic indices were studied in order to find which of them could best forecast the ionospheric response to geomagnetic storms (Mendillo, 1973). Changes in $f_{o} \mathrm{~F} 2$ measurements, with respect to estimated quiet-time values, were used as an ionospheric disturbance index (IDI), that depends on the geomagnetic activity to define a predictive scheme for $f o \mathrm{~F} 2$ (Wrenn et al., 1987; Wrenn and Rodger, 1989). More recently ionospheric disturbances during extreme geomagnetic storms were studied with the aim of developing local forecasting models (Cander and Mihajlovic, 1998).

The ionospheric forecasting empirical local model, to predict the state of the critical frequency of the $\mathrm{F} 2$ layer, $f o \mathrm{~F} 2$, over Rome (IFELMOR), during geomagnetic storms and disturbed ionospheric conditions, was developed with the assumption that there is an empirical relationship between IDI and geomagnetic activity. Since geomagnetic activity can be described with indices that can be established for a few hours in advance, IFELMOR could be used for the short time forecasting of $f_{o} \mathrm{~F} 2$ during disturbed geomagnetic and ionospheric conditions. However, there are two very important factors: the choice of the index most representative of geomagnetic activity and the definition of the reference quiettime values.

Some studies have shown that the extent of significant storm effects depends more on the average value of the geomagnetic index $a_{p}$ rather than the peak value. This means that the magnitude of main phase $f o \mathrm{~F} 2$ deviations could be better described using an integration of $a_{p}$ that takes into account the recent history of geomagnetic activity (Wrenn et al., 1987). The geomagnetic index we used in this study is the index $a_{p}(\tau)$ introduced by Wrenn (1987). It reflects an integration of the geomagnetic activity over a number of 3-h intervals, giving more weight to the recent past and less to measurements from earlier times. Studies concerning the correlation coefficients from linear fitting of the IDI as a function of $\tau$, have shown that for the southern high latitude ionosphere the best fit is obtained for $\tau=0.80$ (Perrone et al., 2001) and for $\tau=0.75$ (Wrenn et al., 1987) while for the middle-high latitude ionosphere the best fit was found for $\tau=0.815$ (Wrenn and Rodger, 1989). Our model is for a middle latitude location (Rome, $41.9^{\circ} \mathrm{N}, 12.5^{\circ} \mathrm{E}$ ) and so we conducted a preliminary study to investigate which $\tau$ value is most suitable. Taking into account the previous results, the values $\tau=0.7, \tau=0.8$, and $\tau=0.9$ were considered and the best fit was found for $\tau=0.9$.

In this study it is also of crucial importance to define the representative $f o \mathrm{~F} 2$ values for the undisturbed ionosphere. Although the monthly median values of $f o \mathrm{~F} 2$ are usually considered as representative of a quiet state of the ionosphere (Cander and Mihajlovic, 1998), in reality it is very difficult to define a parameter that accurately represents the "quiet" ionosphere (Kouris and Fotiadis, 2002).

A review of literature in this field shows that the monthly median values of $f o \mathrm{~F} 2$ give raise to many artificial effects (Kozin et al., 1995). They are inadequate to describe the "quiet" ionospheric behaviour and alternative quiet-time reference values are required (Wrenn et al., 1987). In fact many attempts have been made in the past to define a suitable index to characterize the "quiet" level of the ionosphere (Wrenn et al., 1987; Cooper et al., 1993; Zolesi and Cander, 1998; Belehaki et al., 2000). 


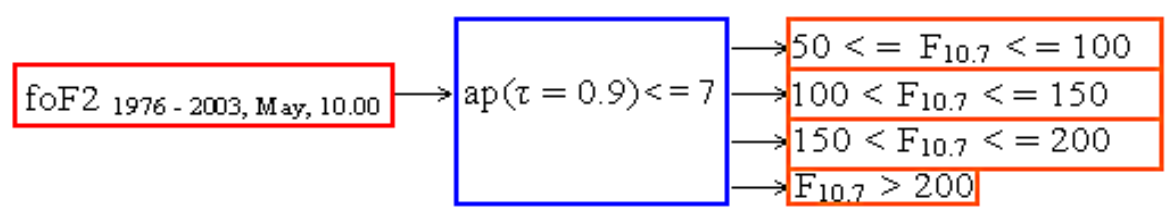

Fig. 1. Scheme followed to select data relative to quiet geomagnetic conditions for 4 different ranges of solar flux.

In order to develop the forecasting procedure, the hourly quiet-time values of $f o \mathrm{~F} 2, f_{o} \mathrm{~F} 2{ }_{Q T}$, estimated following a procedure similar to that devised by Wrenn et al. (1987), the hourly measurements of foF 2 from the Rome observatory, and the hourly time-weighted accumulation series derived from the geomagnetic planetary index $a_{p}, a_{p}(\tau)$, to take into account the recent history of geomagnetic activity (Wrenn, 1987), were considered during the period January 1976-December 2003 (solar cycles 21, 22 and 23). All data considered was selected on the basis of different ranges of $a_{p}(\tau=0.9)$ excluding from the entire data set all the disturbed periods occurring over the years 2000-2003, which were subsequently used to test IFELMOR's performance. For each range selected and for each month, a statistically significant linear correlation was found between the ratio $\log \left(f_{o} \mathrm{~F} 2 / f_{o} \mathrm{~F} 2 Q_{Q T}\right)$ and $a_{p}(\tau=0.9)$.

The coefficients of linear regression obtained for different months and for different ranges of $a_{p}(\tau=0.9)$ and the predicted $a_{p}(\tau=0.9)$ were utilized as input to calculate the shortterm ionospheric forecasting of $f o \mathrm{~F} 2$.

STORM is an empirical storm-time ionospheric correction model developed using data from 43 storms that occurred in the 1980s (Araujo-Pradere et al., 2002). This model was included in the new International Reference Ionosphere (Bilitza, 2001). It provides an estimate of the expected change in the ionosphere during a period of increased geomagnetic activity. STORM provides as output the correction factors to "adjust" the quiet-time values of $f o \mathrm{~F} 2$.

A few comparisons between STORM's performance, IFELMOR's performance, the median measurements and the $f_{o} \mathrm{~F} 2_{Q T}$ values, are shown for significant geomagnetic storm events $\left(a_{p}>150\right)$ and for disturbed ionospheric conditions occurring from 2000 to 2003.

\section{Data analysis and model description}

IFELMOR (Ionospheric Forecasting Empirical Local Model over Rome) was developed using foF 2 measurements taken at the Rome ionospheric observatory from January 1976 to December 2003. The other two parameters utilized for data analysis were the hourly time-weighted accumulation series derived from the geomagnetic planetary index $a_{p}, a_{p}(\tau)$, and the hourly quiet-time reference values of $f o \mathrm{~F} 2\left(f o \mathrm{~F} 2{ }_{Q T}\right)$ estimated following a method analogous to that elaborated by Wrenn (1987).

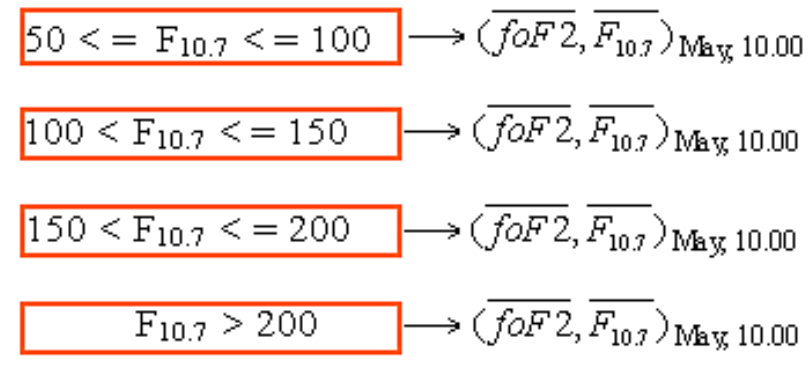

Fig. 2. The mean values of $f o \mathrm{~F} 2$ and $\mathrm{F} 10.7$ are extracted from each range of solar flux selected for a given month (May) and hour (10:00).

The hourly quiet-time reference values of $f_{o} \mathrm{~F} 2$ were calculated in the following way: all the measurements of foF2 from 1976 to 2003 for a given month (e.g. May) and for a selected hour (e.g. 10:00) were extracted for $a_{p}(\tau=0.9) \leq 7$ to select data relative to quiet geomagnetic conditions and binned in terms of 4 ranges of 10.7 solar flux $\left(\mathrm{F}_{10.7}\right)$ (Fig. 1).

For each range of $\mathrm{F}_{10.7}$ selected (50-100, 100-150, 150 $200,200-250 \times 10^{-22} \mathrm{~W} \mathrm{~m}^{-2}$ ), mean values of $f o \mathrm{~F} 2$ and $\mathrm{F}_{10.7}$ were calculated for the hour and month under consideration (Fig. 2).

This procedure repeated for all the $24 \mathrm{~h}$ provides four sets of quiet-time $f_{o} \mathrm{~F} 2$ profiles for the month of May (Fig. 3). The procedure is then repeated for all the months of the year to obtain four sets of quiet-time foF 2 profiles for each month.

For any hour of any day of any month, the quiet-time reference hourly values of $f_{o F} 2\left(f o F 2{ }_{Q T}\right)$ from 1976 to 2003 were computed by means of an appropriate linear interpolation involving the four sets of quiet-time $f_{o} \mathrm{~F} 2$ profiles and the known daily value of $\mathrm{F}_{10.7}$. Figure 4 shows an example calculation of $f_{o F}{ }_{Q T}$ for 5 May 1984 at 12:00 UT.

\subsection{Forecasting procedure}

For any hour of any day of any month from 1976 to 2003, the ratios $\log \left(f_{o} \mathrm{~F} 2 / f_{o} \mathrm{~F} 2{ }_{Q T}\right)$ were calculated and binned in terms of 6 ranges of $a_{p}(\tau=0.9): a_{p}(\tau=0.9) \geq 32, a_{p}(\tau=0.9) \geq 50$, $a_{p}(\tau=0.9) \geq 70, \quad a_{p}(\tau=0.9) \geq 90, \quad a_{p}(\tau=0.9) \geq 110, \quad$ and $a_{p}(\tau=0.9) \geq 140$ (Fig. 5a) excluding from the entire data set the disturbed periods occurring during the years 20002003, which will be used to test IFELMOR's performance (Table 1). 


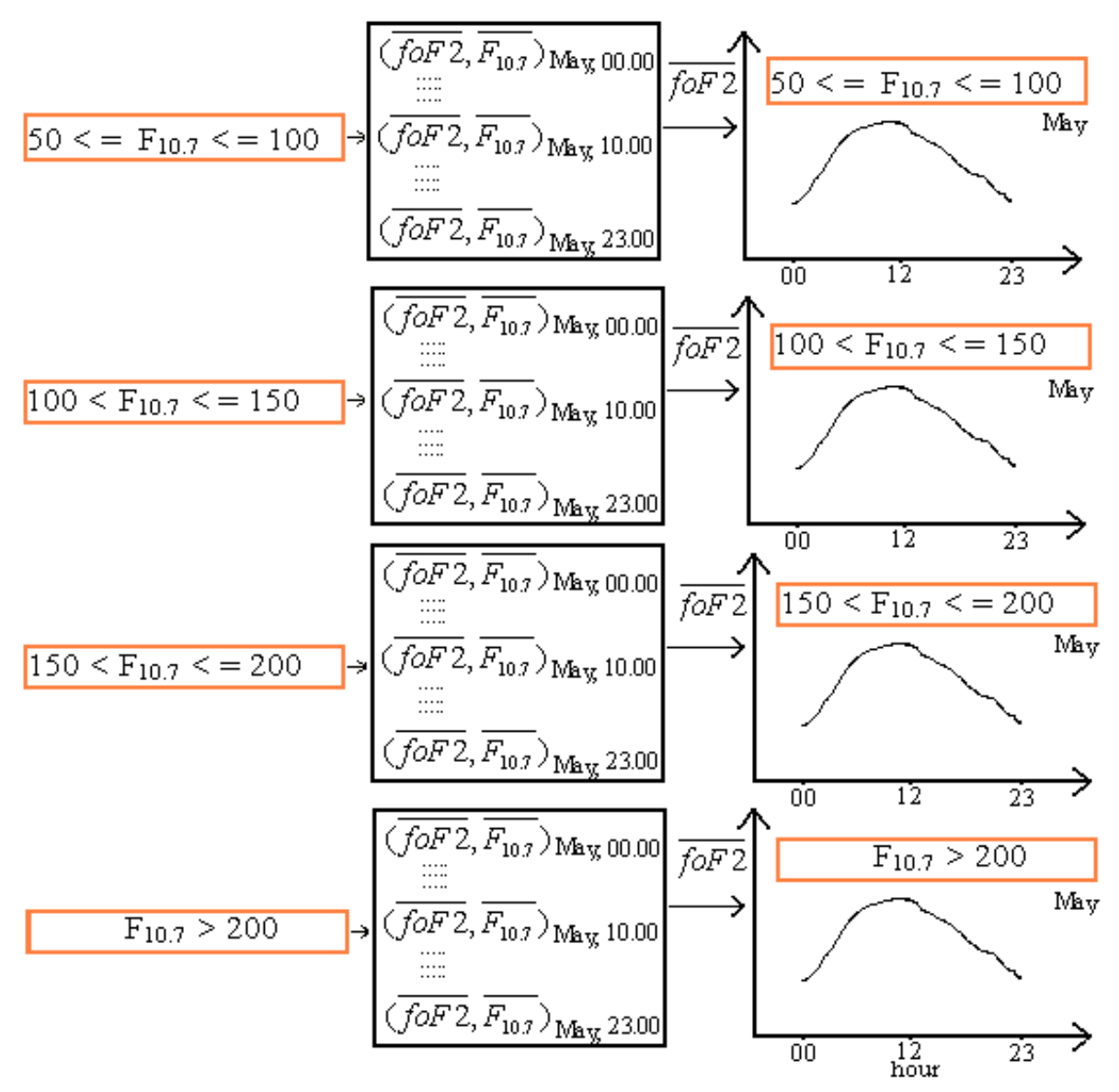

Fig. 3. Scheme followed to obtain the quiet-time foF 2 profiles from each range of solar flux selected for a given month (May).

Table 1. Periods chosen to test IFELMOR and STORM models.

\begin{tabular}{ll}
\hline Period & $a_{p} \max$ \\
\hline 24-25 May 2000 & 207 \\
15-16 July 2000 & 400 \\
4-5 October 2000 & 179 \\
31 March-1-2 April 2001 & 300 \\
12-13 April 2001 & 154 \\
6-7 November 2001 & 300 \\
2-3 October 2002 & 154 \\
30-31 May 2003 & 154 \\
19-22-23 August 2003 & 154 \\
30-31 October-1 November 2003 & 400 \\
21-22 November 2003 & 300 \\
\hline
\end{tabular}

A further selection for each bin was made extracting all data in which the differences between the values of $f o \mathrm{~F} 2 Q T$ and $f o \mathrm{~F} 2$ were $\geq 1 \mathrm{MHz}, \geq 2 \mathrm{MHz}, \geq 3 \mathrm{MHz}$ and $\geq 4 \mathrm{MHz}$, in order to select data relative to various disturbed geomagnetic and ionospheric conditions (Fig. 5b).
Subsequently this data was binned in terms of single month, winter months (January, February, November, and December), equinoctial months (March, April, September, and October), summer months (May, June, July, and August) and in terms of all the months (January, February,..., December). The procedure followed is shown in Fig. 6 only for the case $a_{p}(\tau=0.9) \geq 32$.

Each bin includes a large set of hourly time-series of $\log \left(f o \mathrm{~F} 2 / f o \mathrm{~F} 2{ }_{Q T}\right)$ and $a_{p}(\tau=0.9)$ on which a linear regression analysis is performed.

On the basis of the procedure described above, 384 $(16 \times 6 \times 4)$ pairs of regression coefficients were calculated assuming the following statistical model:

$\log \frac{f o \mathrm{~F} 2}{f o \mathrm{~F} 2 Q T}=A+B \cdot a_{p}(\tau=0.9)$

The numerical coefficients A and B were calculated by means of the least squares method. Each pair of coefficients represents a potential model to use for short-term forecasting of $f o \mathrm{~F} 2$.

For each model a Fisher's test (confidence level $=95 \%$ ) was performed to check its statistical significance (SS). In this way many coefficients were discarded. The remaining 


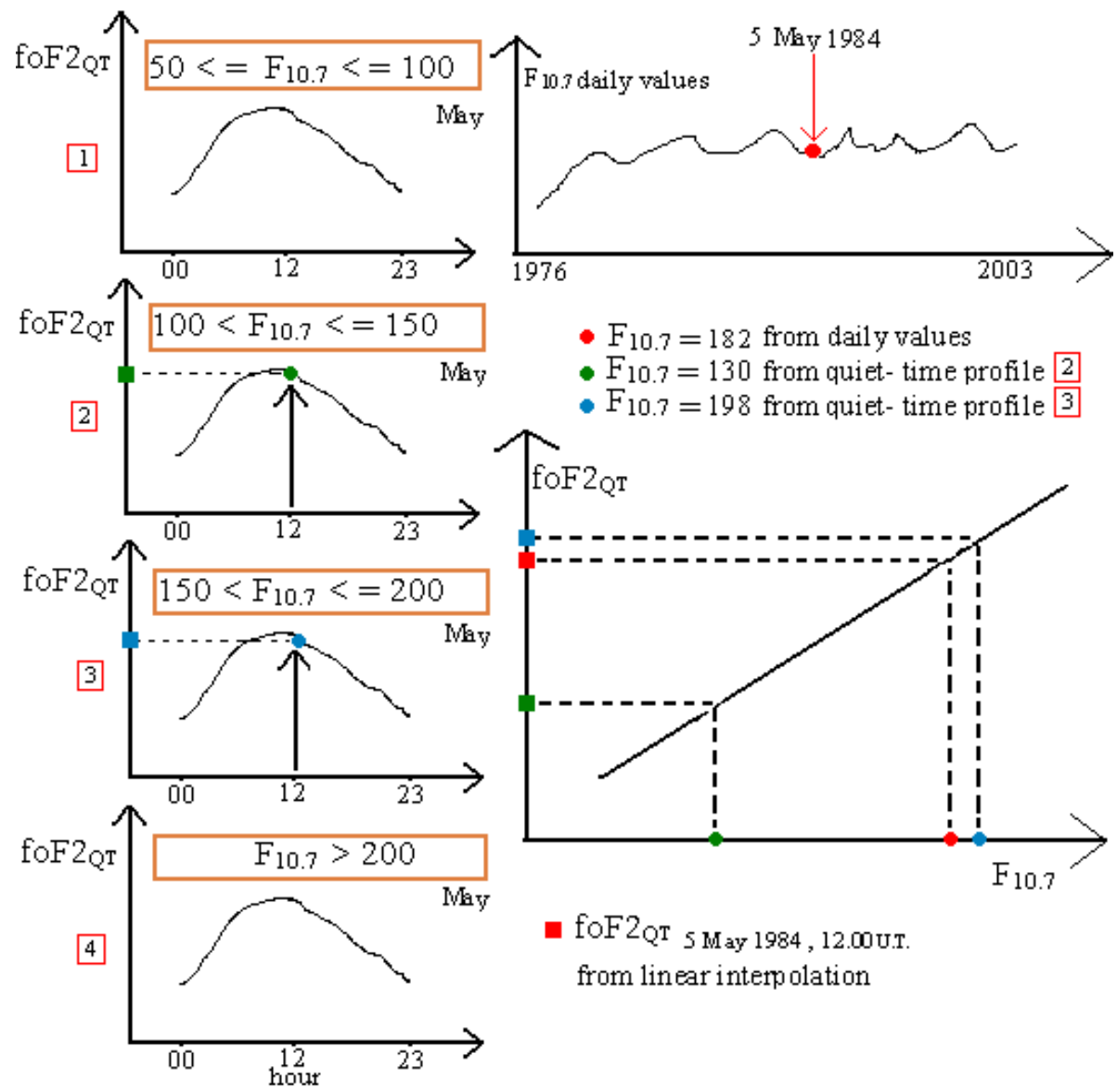

Fig. 4. An example of the procedure followed to calculate the quiet-time value of $f o F 2$ for a given day (5 May 1984) and hour (12:00 UT).

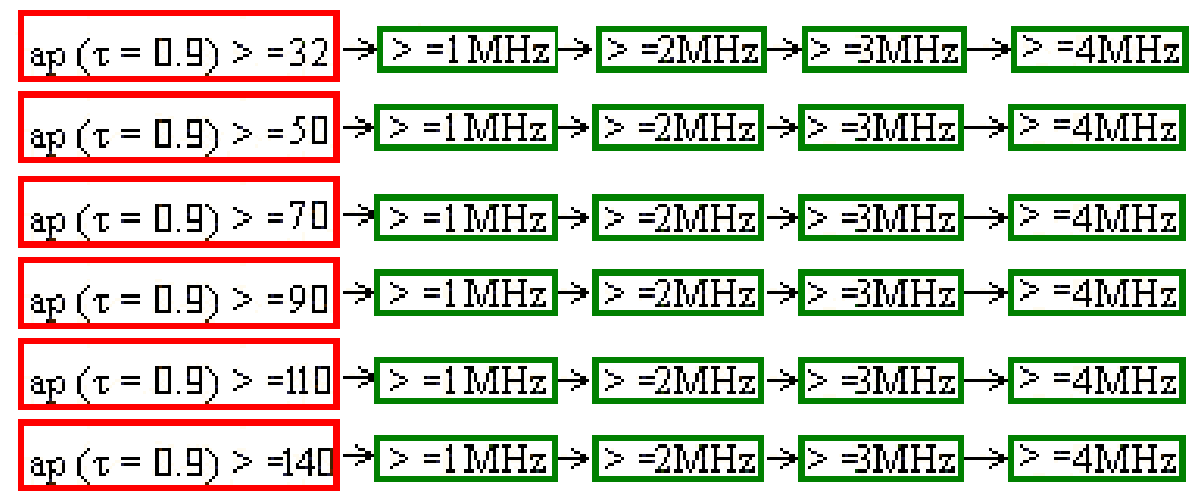

(a) (b)

Fig. 5. Scheme followed to select data relative to different disturbed magneto-ionospheric conditions.

coefficients are the candidates for use in the prediction of $f o \mathrm{~F} 2$. We refer to them hereafter as $\left(A_{S S}, B_{S S}\right)$.

The prediction algorithm depends on the regression coefficients $A$ and $B$, as shown in Eq. (2).

$f_{o \mathrm{~F}} 2_{\text {predicted }}=f o \mathrm{~F} 2{ }_{Q T} \cdot \exp ^{A+B \cdot a_{p}(\tau=0.9)}$
An analysis conducted "a priori" to find the model that gives the best performance among the ones with statistical significance was performed in the following way: all the hourly measurements of $f o \mathrm{~F} 2$ from 1976 to 2003 relative to a given month (e.g. May) were binned in terms of 6 ranges of $a_{p}(\tau=0.9)$ : 


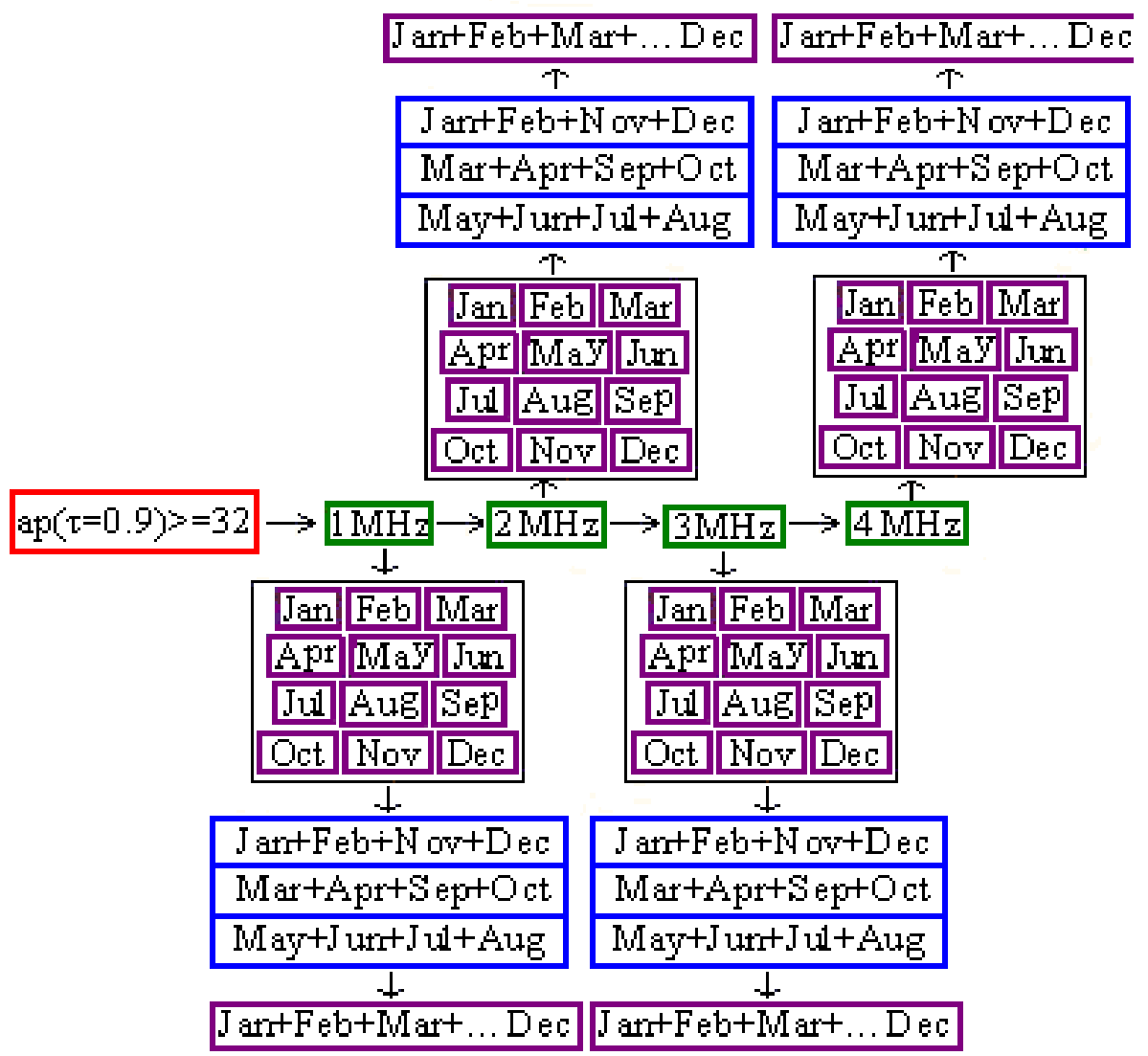

Fig. 6. Scheme followed to select data relative to single months, winter months, equinoctial months, summer months and all the months for the case $a_{p}(\tau=0.9) \geq 32$.

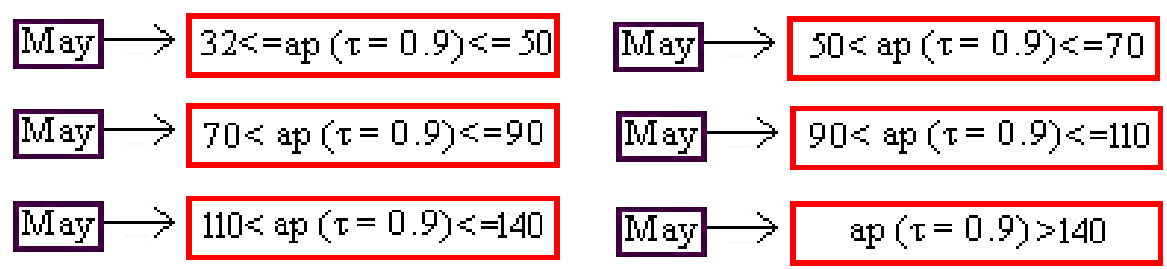

Fig. 7. Example of scheme followed to select data relative to 6 different disturbed geomagnetic conditions for a given month (May).

$32 \leq a_{p}(\tau=0.9) \leq 50 ; 50<a_{p}(\tau=0.9) \leq 70 ; 70<a_{p}(\tau=0.9) \leq 90 ;$

$90<a_{p}(\tau=0.9) \leq 110 ; 110<a_{p}(\tau=0.9) \leq 140 ; a_{p}(\tau=0.9)>140$

(Fig. 7).

The pairs of regression coefficients $\left(A_{S S}, B_{S S}\right)$ were utilized to calculate the predictions over the time series of data included inside each bin.

By varying the pairs of coefficients, for a given bin (e.g. $\left.32 \leq a_{p}(\tau=0.9) \leq 50\right)$, different predictions for $f o \mathrm{~F} 2$ are generated and compared with the measurements by evaluating the value of the root mean square deviation (r.m.s.). The r.m.s. in function of $\left(A_{S S}, B_{S S}\right)$ is given by

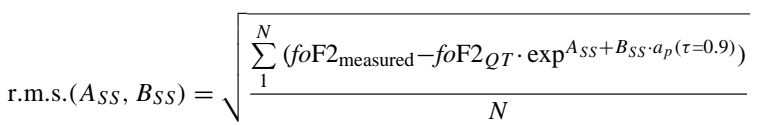

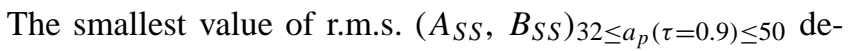

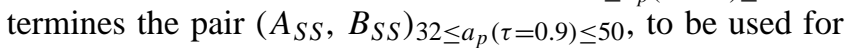
the prediction of $f_{o} \mathrm{~F} 2$ during disturbed magneto-ionospheric conditions in May when $32 \leq a_{p}(\tau=0.9) \leq 50$. The procedure is then repeated to obtain the pairs of regression coefficients relative to the other bins and months of the year. The pairs of coefficients thus obtained are used in Eq. (2), to calculate the ionospheric forecasting of $f o \mathrm{~F} 2$. 
Table 2. Comparisons in terms of r.m.s. for all the days selected under disturbed ionospheric conditions; the best performance is labelled in bold.

\begin{tabular}{llllll}
\hline Day/month/year & $\begin{array}{l}\text { IFELMOR } \\
\text { r.m.s. }(\mathrm{MHz})\end{array}$ & $\begin{array}{l}\text { STORM } \\
\text { r.m.s. (MHz) }\end{array}$ & $\begin{array}{l}\text { MEDIANS } \\
\text { r.m.s. (MHz) }\end{array}$ & $\begin{array}{l}\text { STORM } \\
\text { r.m.s. }(\mathrm{MHz} 2 Q T\end{array}$ & $\begin{array}{l}f o F 2 Q T \\
\text { r.m.s. }(\mathrm{MHz})\end{array}$ \\
\hline Global r.m.s. error on 270 samples & $\mathbf{1 . 3 8}$ & 1.72 & 1.86 & 3.15 & 3.41 \\
\hline
\end{tabular}

Table 3. Comparisons in terms of r.m.s. for the days selected under disturbed ionospheric conditions with $\overline{a_{p}(\tau=0.9)} \leq 50$; the best performance is labelled in bold.

\begin{tabular}{|c|c|c|c|c|c|c|}
\hline Day/month/year & $\begin{array}{l}\text { IFELMOR } \\
\text { r.m.s. }(\mathrm{MHz})\end{array}$ & $\begin{array}{l}\text { STORM } \\
\text { r.m.s. }(\mathrm{MHz})\end{array}$ & $\begin{array}{l}\text { MEDIANS } \\
\text { r.m.s. (MHz) }\end{array}$ & $\begin{array}{l}\text { STORM }_{f o F} 2 Q T \\
\text { r.m.s. }(\mathrm{MHz})\end{array}$ & $\begin{array}{l}f_{O F} 2 T \\
\text { r.m.s. } \\
(\mathrm{MHz})\end{array}$ & $\overline{a_{p}(\tau=0.9)}$ \\
\hline 22 November 2003 & 1.08 & 0.52 & 0.54 & 1.70 & 1.41 & 44.7 \\
\hline $\begin{array}{l}\text { Global r.m.s. error on } \\
48 \text { samples }\end{array}$ & 0.87 & 0.49 & 0.68 & 1.27 & 1.44 & \\
\hline
\end{tabular}

\section{Testing procedure comparisons and results}

A few significant geomagnetic storm events $\left(a_{p}>150\right)$ occurring from 2000 to 2003 were taken into account to compare the IFELMOR model with the STORM model (Table 1).

The STORM model provides a correction factor (CF) for each hour, depending on the geomagnetic latitude, and this is used to "correct" the quiet-time value of $f_{o} \mathrm{~F} 2$. Therefore, for a comparison with IFELMOR, the correction factors were calculated for all the $24 \mathrm{~h}$ of the day for the geomagnetic latitude $+40 \mathrm{~N}^{\circ}\left(\mathrm{CF}_{40 \mathrm{~N}^{\circ}}\right)$. Since STORM can scale the output of any quiet-time ionospheric model, the 24 hourly median measurements of $f_{o} \mathrm{~F} 2, f_{o} \mathrm{~F} 2$ MEDIANS, as well as the 24 hourly values, $f o \mathrm{~F} 2 Q T$, were considered as the quiet-time ionospheric levels of $f_{o} \mathrm{~F} 2$. The STORM prediction at a given hour, $h$, was calculated in two different cases by the Eqs. (45).

$\mathrm{STORM}_{\text {MEDIANS }, \mathrm{h}}=\mathrm{CF}_{40 \mathrm{~N}^{\circ}, \mathrm{h}} \cdot f_{o \mathrm{~F}} 2_{\text {MEDIANS }, \mathrm{h}}$

$\mathrm{STORM}_{f o \mathrm{~F} 2 \mathrm{QT}, \mathrm{h}}=\mathrm{CF}_{40 \mathrm{~N}^{\circ}, \mathrm{h}} \cdot f_{o \mathrm{~F}}{ }_{Q T, h}$

Subsequently an analysis was conducted to study the behaviour of IFELMOR under disturbed ionospheric conditions connected with the selected disturbed geomagnetic periods.

To establish when a disturbed ionospheric condition occurs, the time-profiles of $f_{o} \mathrm{~F} 2, f_{o F} 2_{Q T},\left(f o \mathrm{~F} 2-f o \mathrm{~F} 2_{Q T}\right)$, and $a_{p}(\tau=0.9)$ were considered. The disturbed ionospheric conditions connected to negative ionospheric storms were selected adopting the following criterion: at least seventy per cent of the differences $\left(f_{o} \mathrm{~F} 2-f_{o F} 2_{Q T}\right)$ must be below the level $\leq-1 \mathrm{MHz}$. On the basis of this criterion 13 periods related to negative ionospheric storms were extracted. Figures 8-10 show a few examples of the selected disturbed ionospheric periods.

Table 2 shows the comparisons between IFELMOR, STORM MEDIANS, the median measurements, STORM $_{f_{O F} Q T T}$, and the $f_{o F}{ }_{Q T}$ values in terms of r.m.s. for all the 13 days selected under disturbed ionospheric conditions.

The Tables 3-5 show the comparisons in terms of r.m.s. for the days selected under disturbed ionospheric conditions for different ranges of the daily mean of $a_{p}(\tau=0.9): \quad \overline{a_{p}(\tau=0.9)} \leq 50$ (moderately disturbed days),

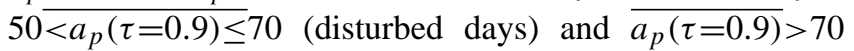
(very disturbed days).

\section{Discussion of the results and future developments}

The analysis carried out gave the following results. At least in the cases analysed, during strong, severe, and extreme geomagnetic storms events, it was assessed that under disturbed ionospheric conditions related to negative ionospheric storms effects, IFELMOR's performance, calculated in terms of r.m.s. taking into account all the 13 days selected, is better (r.m.s.=1.38) than STORM MEDIANS (r.m.s.=1.72) and the median measurements (r.m.s.=1.86). In particular, IFELMOR provides much better predictions with 


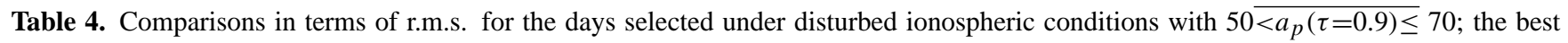
performance is labelled in bold.

\begin{tabular}{|c|c|c|c|c|c|c|}
\hline Day/month/year & $\begin{array}{l}\text { IFELMOR } \\
\text { r.m.s. (MHz) }\end{array}$ & $\begin{array}{l}\text { STORM } \\
\text { r.m.s. (MHz) }\end{array}$ & $\begin{array}{l}\text { MEDIANS } \\
\text { r.m.s. (MHz) }\end{array}$ & $\begin{array}{l}\text { STORM }_{f o F} 2 Q T \\
\text { r.m.s. }(\mathrm{MHz})\end{array}$ & $\begin{array}{l}\text { foF2 } Q T \\
\text { r.m.s. } \\
(\mathrm{MHz})\end{array}$ & $\overline{a_{p}(\tau=0.9)}$ \\
\hline 24 May 2000 & 0.86 & 1.05 & 1.30 & 0.98 & 2.06 & 51.4 \\
\hline 15 July 2000 & 1.35 & 1.11 & 1.70 & 1.03 & 1.91 & 63.0 \\
\hline 6 November 2001 & 2.70 & 3.62 & 3.30 & 3.88 & 3.57 & 66.8 \\
\hline 30 May 2003 & 0.93 & 0.71 & 0.75 & 0.85 & 2.42 & 69.5 \\
\hline $\begin{array}{l}\text { Global r.m.s. error on } \\
84 \text { samples }\end{array}$ & 1.66 & 2.04 & 2.17 & 2.15 & 2.57 & \\
\hline
\end{tabular}

Table 5. Comparisons in terms of r.m.s. for the days selected under disturbed ionospheric conditions with $\overline{a_{p}(\tau=0.9)}>70$; the best performance is labelled in bold.

\begin{tabular}{|c|c|c|c|c|c|c|}
\hline Day/month/year & $\begin{array}{l}\text { IFELMOR } \\
\text { r.m.s. (MHz) }\end{array}$ & $\begin{array}{l}\text { STORM MEDIANS } \\
\text { r.m.s. (MHz) }\end{array}$ & $\begin{array}{l}\text { MEDIANS } \\
\text { r.m.s. (MHz) }\end{array}$ & $\begin{array}{l}\text { STORM }_{f o \mathrm{~F} 2} Q T \\
\text { r.m.s. }(\mathrm{MHz})\end{array}$ & $\begin{array}{l}{ }_{f o F} 2 Q T \\
\text { r.m.s. } \\
(\mathrm{MHz})\end{array}$ & $\overline{a_{p}(\tau=0.9)}$ \\
\hline 31 March 2001 & 1.70 & 2.81 & 2.97 & 4.11 & 4.48 & 77.1 \\
\hline 1 April 2001 & 1.54 & 1.71 & 1.98 & 2.02 & 3.34 & 78.7 \\
\hline 30 October 2003 & 0.87 & 1.87 & 1.89 & 6.78 & 6.83 & 125.1 \\
\hline 21 Novembre 2003 & 0.73 & 0.76 & 0.80 & 1.55 & 1.40 & 77.8 \\
\hline $\begin{array}{l}\text { Global r.m.s. error on } \\
138 \text { samples }\end{array}$ & 1.34 & 1.78 & 1.94 & 4.02 & 4.25 & \\
\hline
\end{tabular}

respect to $\mathrm{STORM}_{f o \mathrm{~F} 2 Q T}$ (r.m.s.=3.15) and the $f_{o \mathrm{~F}}{ }_{Q T}$ values (r.m.s.=3.41) (Table 2).

For disturbed magnetic conditions $\left(50<\overline{a_{p}(\tau=0.9)} \leq 70\right)$, the differences (r.m.s.STORM MEDIANS - r.m.s.IFELMOR) and (r.m.s.MEDIANS -r.m.s.IFELMOR) are equal to $0.38 \mathrm{MHz}$ and $0.51 \mathrm{MHz}$ respectively (Table 4). For very disturbed magnetic conditions $\left(\overline{a_{p}(\tau=0.9)}>70\right)$, the differences (r.m.s.STORM MEDIANS - r.m.s.IFELMOR) and (r.m.s.MEDIANS -r.m.s.IFELMOR) are equal to $0.44 \mathrm{MHz}$ and $0.60 \mathrm{MHz}$, respectively (Table 5).

This means that during negative ionospheric storms effects, the performance of IFELMOR is better compared to

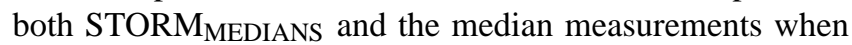
geomagnetic activity increases.

It must also be noted that for each range of geomagnetic activity selected, IFELMOR's performance is always much better (r.m.s.=0.87; r.m.s.=1.66; r.m.s.=1.34) than that provided by STORM $_{f_{O F} Q T T}$ (r.m.s.=1.27; r.m.s.=2.15; r.m.s.=4.02) and by the $f_{o F} 2{ }_{Q T}$ values (r.m.s.=1.44; r.m.s.=2.57; r.m.s.=4.25) as shown in Tables 3-5. In particular, for disturbed magnetic conditions, the difference (r.m.s.STORM $f_{o F} 2_{Q T}-$ r.m.s.IFELMOR) is equal to $0.49 \mathrm{MHz}$ and the difference (r.m.s. $f_{o} \mathrm{~F}_{Q T}-$ r.m.s.IFELMOR) is equal to $0.91 \mathrm{MHz}$ (Table 4). For very disturbed magnetic conditions, these differences are larger with (r.m.s. ${ }_{\text {STORM } f o F 2_{Q T}}$-r.m.s.IFELMOR) equal to $2.68 \mathrm{MHz}$ and (r.m.s. $f_{O F} 2_{Q T}$ r.m.s. IFELMOR) equal to $2.91 \mathrm{MHz}$ (Table 5). Therefore, when the geomagnetic activity increases, the performance of IFELMOR shows a remarkable improvement compared with the performance provided by STORM when the modeled quiet-time values, $f_{o \mathrm{~F}} 2_{Q T}$, are scaled in place of the median measurements.

Even if it was presumed that the median measurements and the $f_{o} \mathrm{~F} 2{ }_{Q T}$ values would have a poor performance during an ionospherically disturbed period, the comparison with IFELMOR was carried out anyway to confirm that under disturbed ionospheric conditions IFELMOR's performance is better than that provided by any possible "parameter" that 


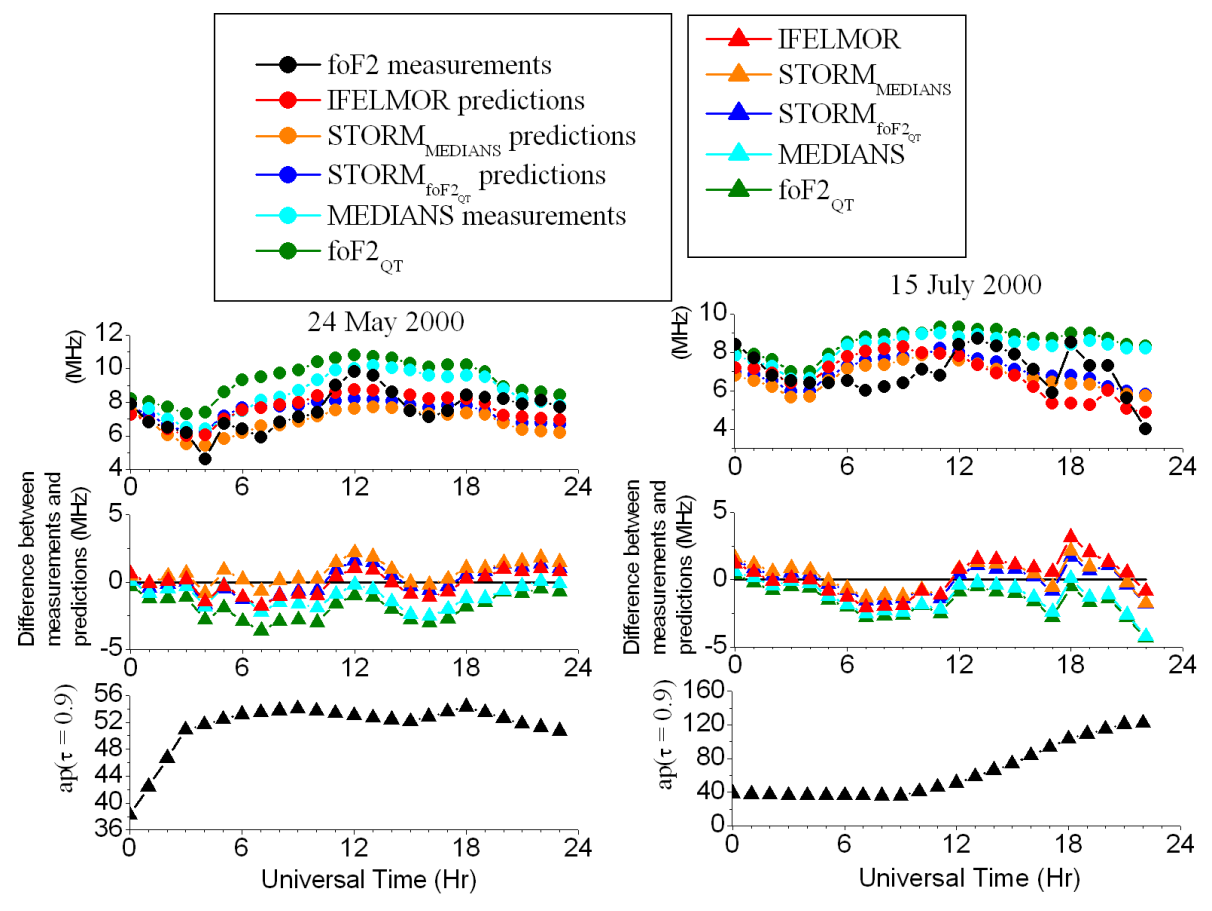

Fig. 8. Results for disturbed ionospheric conditions on 24 May and 15 July 2000. In the upper panels the black plots show the $f o F 2$ measurements; the red plots show the predictions of $f o \mathrm{~F} 2$ obtained with IFELMOR; the yellow plots show the predictions of $f o F 2$ obtained with STORM MEDIANS; the blue plots show the predictions of $f o \mathrm{~F} 2$ obtained with $\mathrm{STORM}_{f o \mathrm{~F} 2 Q T}$; the cyanic plots show the median measurements; the green plots show the hourly quiet-time values of $f o \mathrm{~F} 2$.

In the middle panels the red plots show the differences between the $f o \mathrm{~F} 2$ measurements and the $f o \mathrm{~F} 2$ predictions obtained with IFELMOR; the yellow plots show the differences between the $f o \mathrm{~F} 2$ measurements and the $f o \mathrm{~F} 2$ predictions obtained with STORM MEDIANS; the blue plots show the differences between the $f_{o} \mathrm{~F} 2$ measurements and the $f o \mathrm{~F} 2$ predictions obtained with $\mathrm{STORM}_{f o \mathrm{~F} 2} Q T$. For a further comparison the differences between the $f o \mathrm{~F} 2$ measurements and the median measurements (cyanic plots), and the differences between the $f o \mathrm{~F} 2$ measurements and the $f o \mathrm{~F} 2{ }_{Q T}$ values (green plots) are also shown. Some parts of the plots do not appear because of an overlap effect. The horizontal line marks the $0 \mathrm{MHz}$ level (no difference observed). In the lower panels the black plots show the hourly values of the geomagnetic index $a_{p}(\tau=0.9)$.

IFELMOR works better than both STORM MEDIANS and STORM $f_{O F 2 Q T}$ for the day 24 May 2000 while for the day 15 July 2000 better predictions are provided by $\mathrm{STORM}_{f O \mathrm{~F} 2 Q T}$. However the comparison between the models does not show significant differences, especially for the day 24 May 2000, as is confirmed by the values of the r.m.s. reported in Table 4. In both cases the worst performance is the median measurements and the $f o \mathrm{~F}^{2} Q T$ values.

represents the quiet-time ionosphere. This confirmation is thought to be an important requirement to propose the model for short-term forecasting purposes during disturbed ionospheric conditions.

Further analysis concerning other disturbed periods still needs to be performed, as well as comparisons with other short-term forecasting methods to further test the efficiency of the model and better understand its behaviour.

Even though improvements could be obtained taking into account regression coefficients depending on the hour, defining the normal level of the undisturbed ionosphere in a different way from the one described above and trying to use different geomagnetic indices, it is the opinion of the authors that the results obtained by IFELMOR are globally satisfactory in particular for the periods characterized by high geomagnetic activity and very disturbed ionospheric conditions.
As the prediction of $\mathrm{F}_{10.7}$ is given from 1 to 27 days in advance (see http://www.nwra-az.com/spawx/27do.html), the quiet-time values of $f_{o} \mathrm{~F} 2$ can easily be calculated at least 1 day ahead for all the $24 \mathrm{~h}$ following the procedure described in Fig. 4. The forecasting algorithm (Eq. 2) depends on the geomagnetic index $a_{p}$ and this can easily be derived from the $K_{p}$ index which is predicted for $3 \mathrm{~h}$ ahead (see http://www.sec.noaa.gov/rpc/costello/index.html). Consequently IFELMOR can provide short-term predictions for foF 2 up to $3 \mathrm{~h}$ in advance.

As regards the prediction of geomagnetic activity, many algorithms have been developed. For example, linear prediction filters have been applied to self-predicting the $a_{p}$ index (Thomson et al., 1993) and some improvements in prediction accuracy were found by using a neural network algorithm (Thomson, 1993). Nevertheless, a few studies carried out to 


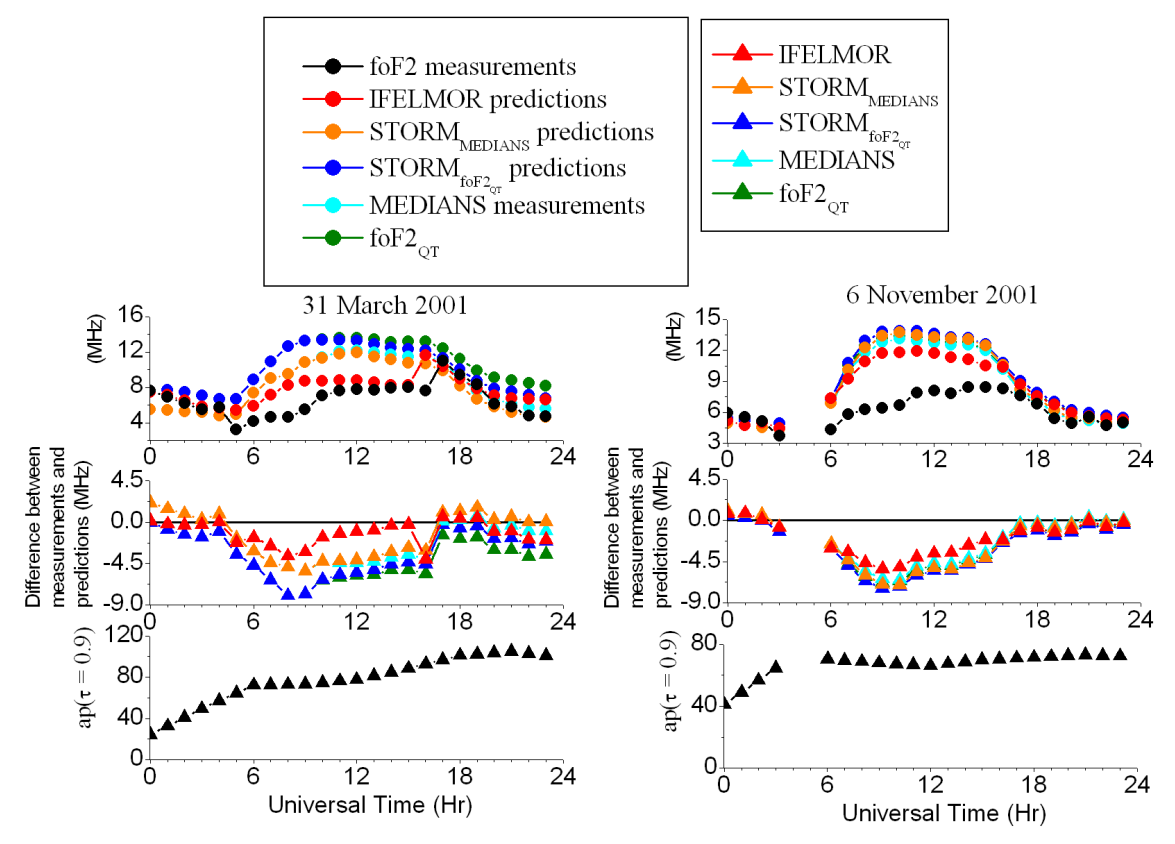

Fig. 9. Same as Fig. 8, but for disturbed ionospheric conditions on 31 March and 6 November 2001. IFELMOR provides much better predictions than both STORM MEDIANS and the median measurements, in particular, IFELMOR's performance is significantly better with respect to $\mathrm{STORM}_{f o \mathrm{~F} 2 Q T}$ and $f_{o \mathrm{~F} 2}{ }_{Q T}$ especially for 31 March 2001 as is confirmed by the values of the r.m.s. reported in Tables 4-5.

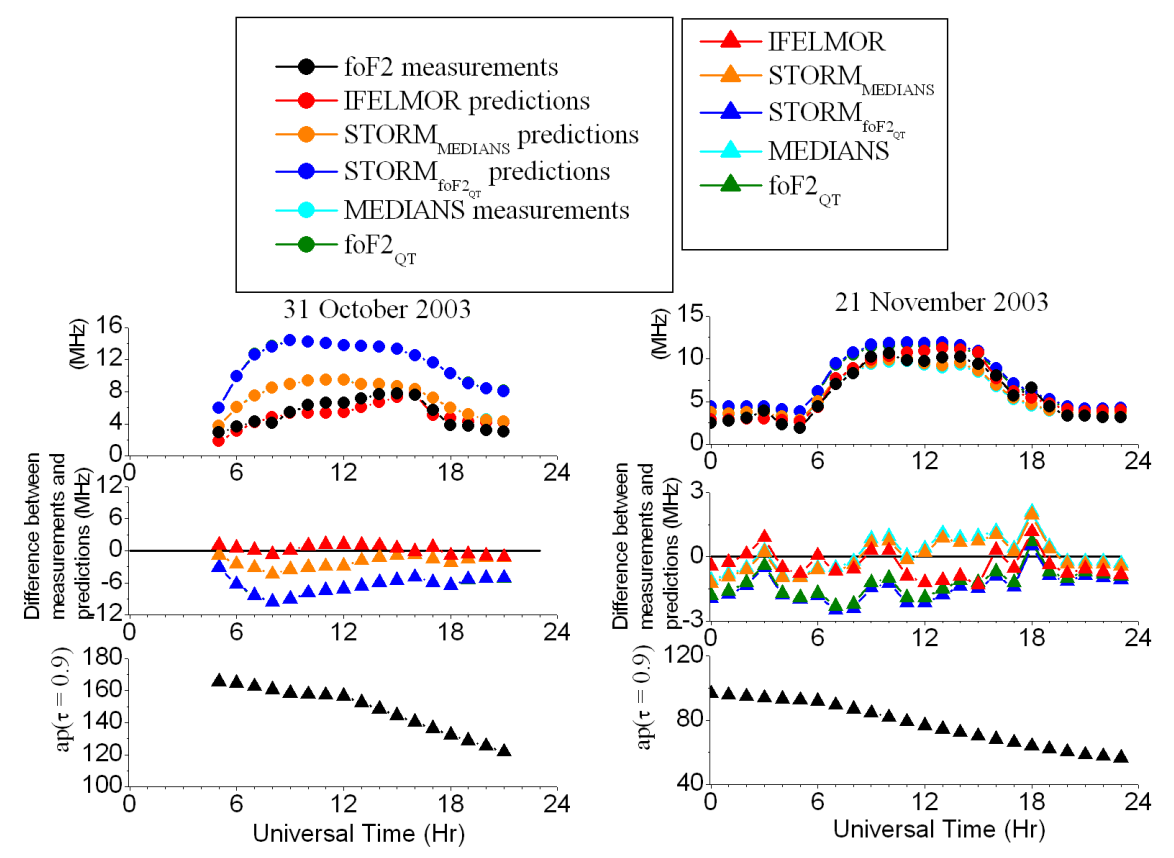

Fig. 10. Same as Fig. 8, but for disturbed ionospheric conditions on 31 October and 21 November 2003. IFELMOR works better than both STORM $_{\text {MEDIANS }}$ and the median measurements for 21 November 2003 even if the comparison does not show significant differences. More significant differences appear from the comparison between IFELMOR and STORM $f_{o F 2} Q T$ as well as between IFELMOR and the $f o F 2$ $Q T$ values as confirmed by the values of the r.m.s. reported in Table 5. IFELMOR provides much better predictions for 31 October 2003 . In

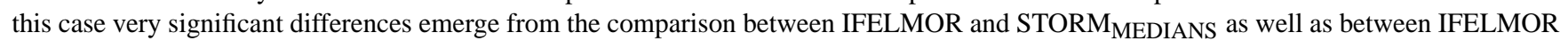
and the median measurements. In particular the comparison between IFELMOR, STORM $f_{f \circ 2} Q T$, and the $f o \mathrm{~F} 2 Q T$ values shows remarkable differences as confirmed by the values of the r.m.s. reported in Table 5. 
verify the forecasting accuracy have shown that, especially in disturbed conditions, geomagnetic index prediction can be disappointing (Joselyn, 1995). This probably occurs because the forecasting techniques do not include an appropriate knowledge of the solar phenomena and magnetospheric influences that cause the geomagnetic activity. However, we trust that in the future the predictions of geomagnetic activity based on observations of solar phenomena and above all the use in real time of near-Earth observations of the approaching solar wind (now-casting) could considerably improve geomagnetic activity forecasting and as a consequence IFELMOR' performance.

It must be noted that our algorithm is station specific and therefore it will not generally be suitable for other midlatitude locations. But, in principle, it can be considered as a part of the prediction and retrospective ionospheric modeling over a given area. In fact the development of other local short-term empirical forecasting models to a number $\mathrm{N}$ of stations could be important to produce a short-term forecasting map of $f o \mathrm{~F} 2$ over the area including the $N$ stations under consideration. Moreover this model applied in connection with a short-term forecasting model for M3000F2 could be used for the forecasting of the MUF for a few hours ahead, improving the frequency management of shortwave radio communication especially under disturbed ionospheric conditions.

The practical application of the proposed short-term forecasting model for operational use in the sense described above is our major goal in the future.

Acknowledgements. The authors would like to thank the GeoForschungs Zentrum Postdam for providing geomagnetic index $a_{p}$, the NOAA's National Geophysical Data Center (NGDC) for providing solar flux data and B. Zolesi for useful comments. The authors are also grateful to the two unknown referees and to P. Wilkinson for his useful comments and suggestions that contributed to improving the paper.

Topical Editor M. Pinnock thanks P. Wilkinson and two other anonymous referees for their help in evaluating this paper.

\section{References}

Araujo-Pradere, E. A., Fuller-Rowell, T. J., and Codrescu, M. V.: STORM: an empirical storm-time ionospheric correction model:1. Model description, Radio Sci., 37(5), 1070, doi:10.1029/2001RS002467, 2002.

Belehaki, A., Moraitis, G., and Tsagouri, I.: On the derivation of an hourly local index to define the normal ionosphere, Annali di Geofisica, 43(1), 189-203, 2000.

Bilitza, D.: IRI 2000, Radio Sci., 36(2), 261-276, doi:10.1029/2000RS002432, 2001.

Bradley, P.: PRIME (Prediction and Retrospective Ionospheric Modelling over Europe), Cost Action 238, Final Report, Rutherford Appleton Laboratory, Chilton Didcot, UK, 1999.

Buonsanto, M. J.: Ionospheric Storms - A review, Space Sci. Rev., 88, 563-601, 1999.
Burns, A. G. and Killen, T. L.:. The equatorial neutral thermospheric response to geomagnetic forcing, Geophys. Res. Lett., 19, 977-980, 1992.

Cander, Lj. R. and Mihajlovic, S. J.: Forecasting ionospheric structure during the great geomagnetic storms, J. Geophys. Res., 103(A1), 391-398, doi:10.1029/97JA02418, 1998.

Cander, Lj. R., Milosavljevic, M. M., Stankovic, S. S., and Tomasevic, S.: Ionospheric forecasting technique by artificial neural network, Electronics Lett., 34(16), 1573-1574, 1998.

Comite Consultatif International des Radio Communications (CCIR): Atlas of ionospheric characteristics, Rep 340-6, Geneva, 1991.

Cooper, J., Barbatsi, K., Gulyaeva, T. L., et al.: PRIME Catalogue of undisturbed days No. 1 in proceedings of COST 238 Workshop, Universitat Graz, Austria, Part 1, 1993.

Fuller-Rowell, T. J., Codrescu, M. V., Roble, R. G., and Richmond, A. D.: How does the thermosphere and ionosphere react to a geomagnetic storm?, in: Magnetic Storms, edited by: Tsurutani, B. T., Gonzales, W. D., Kamide, Y., and Arballo, J. K., Geophysical Monograph 98, American Geophysical Union, Washington, D.C., 1997.

Hanbaba, R.: Improved quality of services ionospheric telecommunication systems planning and operation, Cost Action 251, Final Report, Published by Space Research Centre, Warsaw, Poland, 1999.

Hocke, K. and Schlegel, K.: A review of atmospheric gravity waves and travelling ionospheric disturbances: 1982-1995, Ann. Geophys., 14, 917-940, 1996, http://www.ann-geophys.net/14/917/1996/.

International Telecommunication Union (ITU): ITU-R reference ionospheric characteristics and methods for basic MUF, operational MUF and ray-paths predictions, Recommendation ITU-R P. 1239, Geneva, 1997.

IPS-Radio and Space Services: ASAPS Introductory Booklet, available for download at http://www.ips.gov.au/Products_and_ Services/1/1/2., undated, last accessed March 2006.

Jones, W. B. and Gallet, R. M.: Representation of diurnal and geographical variation of ionospheric data by numerical methods, Telecommun. J., 29, 129-149, 1962.

Joselyn, J. A.: Geomagnetic activity forecasting; the state of the art, Rev. Geophys., 33, 383-401, 1995.

Kouris, S. S. and Fotiadis, D. N.: Ionospheric variability: a comparative statistical study, Adv. Space Res., 29, 977-985, 2002.

Kozin, I. D., Kozin, V. I., and Fedulina, I. N.: On a choice of the ionospheric disturbance indices, Geomagn. Aeron., 35(1), 111112, 1995.

Mendillo, M.: A study of the relationship between geomagnetic storms and ionospheric disturbances at mid-latitudes, Planet. Space Sci., 21, 349-358, 1973.

Muhtarov, P. and Kutiev, I.: Autocorrelation method for temporal interpolation and short-term prediction of ionospheric data, Radio Sci., 34(2), 459-464, 1999.

Oyeyemi, E. O., Poole, A. W. V., and McKinnell, L. A.: On the global short-term forecasting of the ionospheric critical frequency $f o \mathrm{~F} 2$ up to 5 hours in advance using neural networks, Radio Sci., 40(6), RS6012, doi:10.1029/2004RS003239, 2005.

Perrone, L., De Franceschi, G., and Gulyaeva, T. L.: The timeweighted magnetic indices $a_{p}(\tau), \operatorname{PC}(\tau), \operatorname{AE}(\tau)$ and their correlation to the southern high latitude ionosphere, Phys. Chem. 
Earth (C), 26(5), 331-334, 2001.

Pietrella, M., Bianchi. C., and Scotto, C.: Electronic density contours and gravity waves, Il Nuovo Cimento, 20 C(4), 609-612, 1997.

Pietrella, M. and Perrone, L.: Istantaneous Space Weighted Ionospheric Regional Model for instantaneous mapping of the critical frequency of the F2 layer in the European region, Radio Sci., 40(1), RS1005, doi:10.1029/2003RS003008, 2005.

Prölss, G. W.: Ionospheric F region storms, in: Handbook of atmospheric electrodynamics, 2, edited by: Volland, H., CRC Press, Boca Raton, 195-248, 1995.

Prölss, G. W.: Magnetic storm associated perturbations of the upper atmosphere, in: Magnetic Storms, Geophysical Monograph 98, edited by: Tsurutani, B. T., Gonzales, W. D., Kamide, Y., and Arballo, J. K., American Geophysical Union, Washington, D.C., 1997.

Richmond, A. D. and Matsushita, S.: Thermospheric response to a magnetic substorm, J. Geophys. Res., 80, 2839-2850, 1975.

Rishbeth, H., Fuller-Rowell, T. J., and Rees, D.: Diffusive equilibrium and vertical motion in the thermosphere during a severe magnetic storm: a computational study, Planet. Space Sci., 35, 1157-1165, 1987.

Roble, R. G., Richmond, A. D., Oliver, W. L., and Harper, R. M.: Ionospheric effects of the gravity wave launched by the September 18, 1974, Sudden Commencement, J. Geophys. Res., 83, 999-1009, 1978.

Stewart, F. G.: ICEPAC-Technical Manual, available for download at http://www.greg-hand.com/manuals/icepac_tech_manual. pdf, undated.
Testud, J.: Gravity waves generated during magnetic substorm, J. Atmos. Terr. Sci., 32, 1793-1805, 1970.

Titheridge, J. E.: Non periodic irregularities in the ionosphere, J. Geophys. Res., 76, 6955-6960, 1971.

Thomson, A. W. P., Clark, T. D. G., and Kerridge, D. J.: Forecasting $a_{p}$ in the short-term using time series analysis, in Proceedings of the 1992 Solar-Terr. Predictions Workshop, 3, 269, 1993.

Thomson, A. W. P.: Neural networks and non-linear prediction of geomagnetic activity, in: Proceedings of the 1993 International Workshop on Artificial Intelligence Applications in Solar Terrestrial Physics, 133, 1993.

Wrenn, G. L.: Time-Weighted accumulations $a_{p}(\tau)$ and $K_{p}(\tau), \mathrm{J}$. Geophys. Res., 92, 10 125-10 129, 1987.

Wrenn, G. L., Rodger, A. S., and Rishbeth, H.: Geomagnetic storms in Antarctic F region.. I. Diurnal and seasonal patterns in main phase effects, J. Atmos. Terr. Phys., 49, 901-913, 1987.

Wrenn, G. L. and Rodger, A. S.: Geomagnetic modification of the mid-latitude ionosphere: toward a strategy for the improved forecasting of $f_{o}$ F2, Radio Sci., 24(1), 99-111, 1989.

Zolesi, B. and Cander, Lj. R.: Advances in regional ionospheric mapping over Europe, Ann. Geofis., 41(5-6), 827-842, 1998.

Zolesi, B., Belehaki, A., Tsagouri, I., and Cander, Lj. R.: Real-time updating of the Simplified Ionospheric Regional Model for operational applications, Radio Sci., 39(2), RS2011, doi:10.1029/2003RS002936, 2004.

Zolesi, B., Fontana, G., Perrone, L., et al.: A new campaign for oblique-incidence ionospheric sounding over Europe and its data application, J. Atmos. Solar Terr. Phys., in press, 2007. 